\title{
FONOLOGI VARIASI KUMPANG DI SUNGAI KETUNGAU: ANALISIS PERBANDINGAN
}

\author{
Chong Shin \\ Institut Alam dan Tamadun Melayu (ATMA), Universiti Kebangsaan Malaysia \\ chong@ukm.edu.my
}

\begin{abstract}
Abstrak
Makalah ini mendeskripsikan fonologi variasi Kumpang, salah satu variasi Ibanik di Sungai Ketungau, Kalimantan Barat. Kajian ini merupakan sebuah kajian sinkronik yang mendeskriptif bahasa Ibanik kontemporari. Aspek linguistik yang dibincangkan ialah sistem vokal, diftong dan konsonan Kumpang. Dengan membandingkannya dengan data-data Ibanik yang lain, misalnya Demam, Sebaru', Bugau, Banjur dan Iban, kajian ini mempersoalkan kajian-kajian terdahulu tentang jumlah vokal yang terkandung dalam bahasa Ibanik. Analisis terhadap diftong mendapati bahasa Ibanik kaya dengan kosa kata yang berdiftong /-ay/ justeru kerana wujud penjelmaan /*_ an/ dan /-an/ > /-ai/. Dari segi aspek konsonan, didapati fonem yang sepadan dengan $/ \mathrm{\gamma} /$ dalam variasi Kumpang adalah berdiversiti, misalnya muncul sebagai $/ \mathrm{r} /$, /ъ/ ataupun /h/. Begitu juga dengan /-s/. Pada posisi akhir kata, /-s/ muncul sebagai alofon [-ç] atau [-h], bergantung kepada variasi Ibanik tertentu. Berdasarkan data perbandingan, kajian ini telah membuktikan kadar diversiti bahasa Ibanik sebenarnya sangat tinggi di Borneo Barat.
\end{abstract}

Kata Kunci: Ibanik, Kumpang, Vokal, Diftong, Konsonan, Diversiti

The Phonology of Kumpang in Ketungau River: A Comparison Study

\begin{abstract}
This article describes the phonology of Kumpang, an Ibanic variation spoken in Ketungau River, West Kalimantan. In this synchronic study, the vowels, diphthongs and consonants of Kumpang were discussed and compared with other Ibanic varieties such as Demam, Sebaru', Bugau, Banjur and Iban. By analyzing the Kumpang's vowels, it has critised the previous discussions on vowel phonemes in Ibanic studies. The mass of vocabularies with diphthong /-ay/ existed in the Ibanic varieties is identified related to the innovations of $/{ }^{*}$-ay $/$ dan $/{ }^{*}$-an $/>/$-ai/ in this language. In consonants, the discussions of $/ \gamma /$ revealed that this phoneme in correspondence with the consonants of $/ \mathrm{r} /, / \mathrm{b} / \mathrm{or} / \mathrm{h} /$ in other Ibanic varieties, and the /-s/ in the final word position appeared as allophones [-ç] or [-h]. In conclusion,
\end{abstract}


this comparison study has proved that Ibanic is indeed a diversification variety in Western Borneo.

Keywords: Ibanic, Kumpang, Vowel, Diphthong, Consonant, Diversity

\section{Pendahuluan}

Berdasarkan salasilah kekerabatan dan sastera Iban, suku Iban di Sarawak adalah berasal dari lembah Sungai Kapuas, Kalimantan Barat, Indonesia (Sandin, 1968). Pada hakikatnya, di tanah asal Iban, variasi-variasi bahasa yang mirip dengan bahasa Iban (dinamakan sebagai bahasa Ibanik oleh Hudson, 1970) adalah beragam. Begitu juga nama-nama untuk suku ini, dikenal pasti selain suku "Iban", terdapat lebih dari 10 suku yang dikenalpasti setakat ini, misalnya suku Demam, Sebaru', Kupang, Ntabun, Sigarau, Seklau, Skapat, Bugau, Banjur, Kantu', Desa, Ketungau Sesat, Mualang, Semarak, Kumpang dan lain-lain. Istilah Bahasa Ketungau merujuk kepada variasi bahasa Ibanik yang dituturkan di sepanjang Sungai Ketungau, iaitu salah satu cabang Sungai Kapuas; lihat Peta. Antara variasi Ibanik yang terangkum dalam kategori bahasa Ketungau adalah bahasa Demam, Sebaru', Bugau dan Kumpang. Pada hakikatnya, di luar sistem Sungai Ketungau, bahasa Ketungau tersebar di lembah Sekadau (juga satu cabang sungai di hilir Sungai Kapuas). Dari segi struktur linguistik, bahasa Ketungau di lembah Sekadau mempunyai perbezaan fonologi yang jelas dengan variasi di Sungai Ketungau. Di antaranya, bunyi *-an menjelma sebagai /-ai/ dalam bahasa Ketungau (contohnya /pulay/ $\rightarrow$ /pulai/) manakala memaparkan ciri nasalisasi pada bunyi velar di posisi akhir kata dalam bahasa Ketungau Sesat (contohnya /pulan/ $\rightarrow$ /pulã:/) (lihat Collins, 2004). Justeru kerana wujud perbezaan yang nyata, variasi bahasa ini digelar sebagai bahasa Ketungau Sesat oleh penduduk setempat iaitu bahasa yang telah kehilangan ciri-ciri yang ada pada bahasa asli (Lampiran A).

\section{Sorotan Kajian-kajian Lepas}

Di Sarawak, tradisi kajian bahasa dan masyarakat Iban mempunyai sejarah yang agak lama dan penelitian telah mencakupi pelbagai displin ilmu. Hal ini dapat dibuktikan melalui Bibliografi Kajian Iban di Sarawak oleh Lam (2006). Di seberang sempadan politik Sarawak, iaitu Kalimantan Barat (Indonesia), kenyataan adalah sebaliknya. suku peribumi yang menuturkan bahasa yang mirip dengan bahasa Iban yang amat kurang diteliti. Perhatian hanya bermula pada akhir 60-an apabila Hudson memulakan kajian bahasa-bahasa di Borneo Barat (lihat Hudson, 1970). Hudson merupakan peneliti pertama yang mengkategorikan bahasa di Borneo Barat yang memperlihatkan inovasi ${ }^{*}$-an, ${ }^{*}$-an dan ${ }^{*}$-ar kepada /-ai/ sebagai bahasa Ibanik. Selepas usaha Hudson, beberapa penelitian telah dilakukan oleh Collins (2004), Rahim (2005) dan Chong (2006). Collins merintisi pembahasan tentang nomenklatur, distribusi dan aspek fonologi beberapa variasi Ibanik di Kalimantan Barat. Rahim dengan khususnya membincangkan ciri-ciri fonologi dan morfologi dengan varian Mualang dan Kantuk. Kajian Chong pula melengkapi dan mendalami kajian Ibanik 
dengan menghuraikan ciri-ciri Ibanik di Sungai Ketungau dan Sungai Belitang-dua cabang sungai yang menjadi tanah leluhur penutur bahasa Ibanik.

\section{Sekilas tentang Variasi Kumpang}

Makalah ini secara khusus membincangkan salah satu variasi bahasa Ketungau oleh suku Ibanik "minoriti" di Sungai Ketungau, iaitu variasi Kumpang. Dari segi lokasi persebaran, penutur variasi Kumpang terdapat di bahagian hulu sungai tersebut. Antara kampung-kampung yang menuturkan variasi ini adalah seperti Nanga Bayan, Sungai Tanjung, Lebuk Moli, Idai, dan Sepan Peturau. Data yang digunakan dalam makalah ini dikumpulkan dari Nanga Bayan. Secara keseluruhannya, di sepanjang sistem Sungai Ketungau, terdapat dua variasi Ketungau yang menjadi bahasa pengantar, iaitu variasi Demam di bahagian hilir dan varian Sebaru' di bahagian hulu. Setakat ini, belum ada statistik tepat menunjukkan bilangan penutur variasi Kumpang, namun berdasarkan maklumat dari lapangan, suku ini adalah golongan yang minoriti dan mereka adalah masyarakat multilingual dengan menguasai pelbagai variasi bahasa di sekitaranya, misalnya Iban, Bugau, Sebaru', Lebang dan Mualang, selain bahasa Indonesia dan Melayu.

\section{Rekabentuk Kajian dan Metodologi}

Kajian ini merupakan sebuah penelitian berbentuk sinkronik, iaitu kajian deskriptif yang mempelajari bahasa kontemporari tanpa dibandingkan dengan waktu-waktu lain (lihat Chaer, 2003). Kajian diakronik tidak diaplikasikan memandangkan makalah ini hanya berhasrat mengemukakan ciri fonologi linguistik kontemporati bahasa Ibank variasi Kumpang.

Data yang dibincangkan dalam makalah ini diambil dengan kaedah yang sistematik. Sebuah daftar kata yang diolah dari Daftar Kata Swadesh digunakan sebagai panduan mengumpulkan kosa kata. Kata-kata dalam daftar kata ini merangkumi pelbagai aspek, misalnya kata-kata untuk bahagian anggota badan, aktiviti-aktiviti manusia, kata sifat, kata ganti nama, kata nama dan sebagainya. Semasa mengambil data, kata-kata ini diungkapkan dalam bentuk gerak badan dan informan diminta menyebutkan dalam bahasa mereka. Dari segi pemilihan informan, penutur asli bahasa Kumpang (dewasa) yang mempunyai penyebutan yang jelas telah dipilih. Data lisan yang dibekalkan oleh informan dicatatkan dengan menggunakan lambang fonetik standard.

Untuk menganalisis data Kumpang, data-data Ibanik yang lain, iaitu Demam, Sebaru', Banjur, Bugau dan Iban digunakan sebagai data perbandingan. Data-data ini kebanyakan dikumpulkan oleh penulis sendiri, melainkan data Iban yang dipetik dari Dedy (2004) dan Remmy (2009). Tujuan data-data ini dimanfaatkan adalah untuk melihat hubungan linguistik antara variasi-variasi Ibanik secara sepintas lalu. 


\section{Ciri-ciri Linguistik}

Perbincangan seterusnya menghuraikan ciri-ciri linguistik variasi Kumpang. Aspek yang ditinjau meliputi sistem bunyi vokal, konsonan, diftong, serta membandingkan ciri-ciri fonologinya dengan variasi lbanik yang lain.

\section{Vokal}

Secara kumulatif, terdapat empat vokal, iaitu [i], [u], [a], [ə] dalam variasi Kumpang. Berikut merupakan inventori vokal-vokal tersebut:

\begin{tabular}{|c|c|c|c|}
\hline & Depan & Tengah & Belakang \\
\hline Tinggi & $\mathrm{i}$ & & $\mathrm{u}$ \\
\hline Madya & & $\partial$ & \\
\hline Rendah & & a & \\
\hline
\end{tabular}

Rajah 1. Rajah inventori vokal variasi Kumpang

Secara perbandingan, variasi Iban di lembah Saribas (Dedy, 2004) dan Kantuk (Rahim, 2005) masing-masing dilaporkan mengandungi enam vokal, iaitu: [a], $[\mathrm{e}],[\mathrm{i}],[\mathrm{o}],[\mathrm{u}],[ə]$. Ini ternyata berbeza dengan variasi Kumpang yang hanya mengandungi empat vokal sahaja, iaitu: [i], [u], [a], dan [ə].

Dari segi persebaran, vokal [i], [u], dan [a] wujud pada semua posisi dalam kata, tetapi [ə] wujud di posisi suku praakhir pada kata dwisilabik dan suku kedua, ketiga dari akhir pada kata trisilabik. Contohnya:

\section{Vokal Contoh}

[i] [in day] 'ibu', [kiba?] 'kiri', [bətieç] 'betis', [kakiy] 'kaki'

[u] [uyan] 'orang', [tunuok] 'jari', [biluok] 'belok', [siku] 'siku'

[a] [akay] 'akar', [man ${ }^{\mathrm{d} i}$ ?] 'mandi', [naba?] 'menangis', [pa:] 'paha'

[ə] [kədənay] 'berenang', [dəbuw] 'debu'

Bunyi /u/ dalam data Kumpang didapati mengandungi satu alofon, iaitu [o]. Pada posisi suku kata akhir, /u/ wujud sebagai [u] dan juga [o], contohnya:

\section{Lu/sebagai [u]}

[təlup] 'telur'

[butul] 'botol'

[tunku?] 'tungku' 


\title{
Lu/ sebagai [o]
}

\author{
[tumpol] 'tumpul' \\ [nilo?] 'ngilu' \\ [maso?] 'membasuh' \\ [palo?] 'memukul'
}

Untuk /u/ yang wujud sebagai [o], [o] ditafsirkan sebagai alofon kepada /u/ dan bukannya fonem. Dakwaan Dedy (2004) dan Rahim (2005) bahawa /o/ merupakan fonem dalam bahasa Iban perlu disemak lagi kerana /o/ memang tidak pernah wujud pada posisi lain, selain posisi suku kata akhir. Untuk kata Iban yang bentuk leksikalnya sama dengan bahasa Melayu, misalnya kata [uran] (bandingkan dengan [oran] dalam bahasa Melayu), bunyi yang wujud tetap [u].

Terdapat dua ragam bunyi / $\mathrm{u} /$, iaitu sama ada sebagai [u] atau [o], diduga berpunca daripada cara informan melafazkan bunyi tersebut. Memang menjadi satu kelaziman informan bersilih ganti menggunakan kedua-dua bunyi ini. Sebagai contoh, dalam bahasa Iban di Melaban (Saribas), juga didapati mengandungi perbezaan sebutan untuk "telur" dan "basuh", iaitu "telur" sebagai [təlu?] dan "basuh" disebut sebagai [baso?] (lihat Chong, 2003).

Setelah meneliti data-data, kewujudan bunyi [o] dalam bahasa Kumpang dan juga Iban berkaitan dengan ciri geluncuran bahasa-bahasa berkenaan. Sesungguhnya bahasa Iban dan sesetengah bahasa Ibanik (terutamanya variasi bahasa Ketungau) kaya dengan bunyi geluncuran. Terdapat dua bunyi yang lazim terlibat dengan geluncuran, iaitu bunyi [e] dan [o]. Contohnya:

$\begin{array}{ll}\text { [manies] } & \text { 'manis', } \\ \text { [blakeaN] } & \text { 'belakang' } \\ \text { [bien] } & \text { 'van (kenderaan)' } \\ \text { [sien] } & \text { 'sen' } \\ \text { [labuoh] } & \text { 'jatuh' } \\ \text { [duduok] } & \text { 'duduk' }\end{array}$

Dalam erti kata lain, bunyi [o] yang wujud dalam variasi Kumpang turut berstatus bunyi geluncuran kerana variasi bahasa ini mengandungi ciri bunyi ini. Kalau diperhalusi, bunyi geluncuran ini muncul pada kata yang berakhir dengan bunyi velar, seperti seperti $/ \mathrm{k} /, / \mathrm{\gamma} /, \mathrm{h} / \mathrm{dan} / \mathrm{h} /$. Contohnya:

\begin{tabular}{|c|c|}
\hline $\begin{array}{l}\text { [yusuok] } \\
\text { [gəmuok] }\end{array}$ & $\begin{array}{l}\text { 'rusuk' } \\
\text { 'gemuk' }\end{array}$ \\
\hline $\begin{array}{l}\text { [jamuoy] } \\
\text { [dapuoy] }\end{array}$ & $\begin{array}{l}\text { 'jengger' } \\
\text { 'dapur' }\end{array}$ \\
\hline $\begin{array}{l}\text { [bulouh] } \\
\text { [labouh] }\end{array}$ & $\begin{array}{l}\text { 'buluh' } \\
\text { 'iatuh' }\end{array}$ \\
\hline
\end{tabular}


[kampuoN] 'hutan'

[ləmpuoN] 'ringan'

Perlu juga dijelaskan bahawa varian Kumpang tidak mempunyai vokal /e/. Dua kata yang ditemui, iaitu: [le: $\gamma]$ 'leher' dan [jenela] 'tingkap' mungkin diletakkan dalam kategori kata pinjaman sama ada dari bahasa Indonesia ataupun bahasa Melayu. Dalam kata [mənade?] 'adik' atau 'beradik', berkemungkinan [e] turut merupakan alofon kepada /i/.

Dalam dialek Melayu di Sarawak (Collins, 1987), ketinggian bunyi vokal mempengaruhi jenis konsonan nasal velar yang mengikutinya. Contohnya apabila bunyi tinggi [i] muncul di depan nasal $/ \mathrm{h} /$, nasal tersebut akan menjadi $/ \mathrm{h} /$. Sekiranya yang mengikutinya ialah bunyi rendah, bunyi nasal tetap tidak berubah; lihat contoh berikut. Gejala ini ternyata berbeza dalam bahasa Ibanik. Variasi Kumpang memperlihatkan bunyi tinggi [i] pada kedudukan sebelum bunyi nasal $/ \mathrm{g} /$ mengalami geluncuran vokal rendah [a]. Perendahan bunyi vokal dari tinggi ke rendah turut berlaku, iaitu [i] $\rightarrow$ [e]. Berikut adalah antara contohnya:

\section{Dialek Melayu Sarawak Kumpang}

$\begin{array}{lll}\text { [kənin] } & \text { [kənean] } & \text { 'kening' } \\ \text { [dindin] } & \text { [dindean] } & \text { 'dinding' } \\ \text { [dagin] } & \text { [dagean] } & \text { 'daging' }\end{array}$

\section{Diftong}

Terdapat sejumlah tiga diftong dalam varian Kumpang, iaitu: /-ai/, /-ui/ dan /-au/. Contohnya:

$\begin{array}{ll}\text { Maksud } & \text { Kumpang } \\ \text { pulang } & \text { pulai } \\ \text { anjing } & \text { ukui } \\ \text { bau busuk } & \text { buntau }\end{array}$

Seperti yang diterangkan sebelum ini, dalam sesetengah kata, penjelmaan /*-ay/, /*-an/ dan /-ar/ (khas untuk kata "besar") kepada diftong /-ai/ merupakan suatu ciri dignostik untuk bahasa dalam kelompok bahasa Ibanik. Dalam erti kata lain, bahasa Ibanik yang terletak di bawah cabang bahasa Melayik (lihat Adelaar, 1987) dibezakan dengan variasi-variasi Melayik melalui ciri diftong /-ai/ ini. Sekiranya dilihat dari segi kekognatan bahasa Melayik dan Ibanik (misalnya antara dialek Melayu Sarawak dengan bahasa Iban), terdapat banyak kosa kata yang sangat mirip. Boleh dikatakan bahawa bunyi diftong /-ai/ merupakan ciri penanda asas perbezaan kedua-dua bahasa ini. Contohnya: 
Jadual 1

Contoh persamaan dan perbezaan kata-kata dalam Melayik dan Ibanik

\begin{tabular}{ccc}
\hline & Persamaan \\
\hline Kosa Kata & $\begin{array}{c}\text { Dialek Melayu Sarawak } \\
\text { (Melayik) }\end{array}$ & Bahasa Iban (Ibanik) \\
\hline Kera & kəya? & kəra? \\
Dua & dua & dua \\
Hujan & ujan & ujan \\
Ayam & manuk & manuok \\
\hline Pulang & Perbezaan & pulai \\
Datang & Pulan & datai \\
Makan & Datan & makai \\
Besar & Makan & bəsai \\
\hline
\end{tabular}

Walaupun dalam penelitian Collins (2004), bunyi /*-an/ dan /*-an/ mengalami nasalisasi, iaitu bukan sebagai /-ai/ seperti kelaziman, tetapi sebagai [-v)], tinjauan kepada data Ibanik yang lebih banyak, misalnya bahasa Mualang, Seberuang, Demam, Sebaru', Bugau, Remun termasuk Kumpang dan sebagainya, variasi-variasi ini tetap memaparkan bunyi diftong /-ai/. Sesungguhnya sebab wujud bunyi nasalisasi dalam bahasa Ketungau Sesat di lembah Sekadau perlu diteliti lebih lanjut.

\section{Konsonan}

Terdapat 19 konsonan dalam variasi Kumpang. Konsonan-konsonan tersebut adalah seperti dalam rajah inventori berikut:

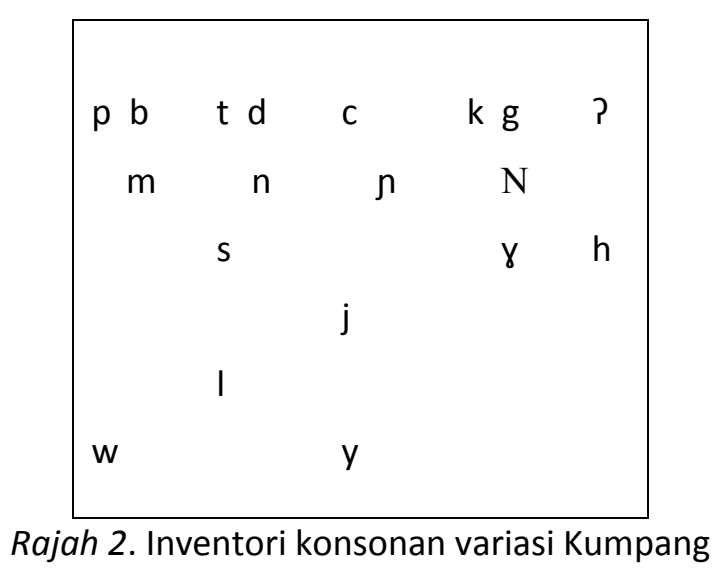

\section{konsonan $/ \gamma /$.}

Daripada 19 konsonan yang disenaraikan, terdapat beberapa konsonan yang wajar diberi huraian. Antaranya, konsonan / $/$ / merupakan antara konsonan yang berupaya menentukan variasi-variasi Ibanik. Kalau merujuk kepada data Ibanik yang banyak, 
didapati wujud kesepadanan konsonan tertentu untuk setiap variasi Ibanik. Pada posisi awal kata, bahasa Seberuang (Kampung Temanang) menyaksikan frikatif velar bersuara $/ \mathrm{y} /$ dilafazkan berserta dengan onset frakatif velar tak bersuara [ $\mathrm{x}$ ]. Pada posisi akhir kata, /y/ disebut sebagai [x], contohnya: ['yan] 'rahang' dan [ipax] 'ipar' (Collins, 2004). Chong (2006) menjelaskan bahawa varian Ketungau (Sebaru' dan Demam), dua variasi Ibanik yang berhubungan sangat erta hanya dapat dibezakan melalui ciri fonetik ini, iaitu bunyi geseran velar $/ \mathrm{\gamma} /$ digunakan dalam variasi Demam dan bunyi uvular / $\mathrm{в} /$ digunakan dalam varian Sebaru'. Bunyi $/ \mathrm{\gamma} /$ dalam variasi Kumpang menyerupai varian Demam, iaitu memaparkan konsonan $/ \mathrm{\gamma} /$. Contohnya:

Jadual 2

/ $\gamma /$ dalam variasi Demam, Sebaru' dan Kumpang

\begin{tabular}{|c|c|c|c|}
\hline Maksud & Demam & Sebaru' & Kumpang \\
\hline Darah & dayah & dаваһ & dayah \\
\hline Kerak & kəyak & kәьак & kəyak \\
\hline Rahang & ya:n & ва:п & ya:n \\
\hline Ipar & ipaey & ірав & ipay \\
\hline
\end{tabular}

Berdasarkan huraian, jelas bahawa di Kalimantan Barat, konsonan $/ \gamma /$ memaparkan pelbagai kesepadanan dalam variasi Ibanik, iaitu sebagai [- $\mathrm{x}],[\gamma]$ atau [в]. Begitu juga dengan bahasa Iban di Sarawak. Walaupun di bawah satu nama yang seragam, iaitu "bahasa Iban", ini bukan bermaksud bahawa bahasa Iban tidak bervariasi. Kajian Remmy (2009) telah menunjukkan konsonan /r/ digunakan dalam variasi Iban Standard, Saribas dan Lundu manakala /h/ yang sepadan dengan / $/$ / digunakan di daerah Samarahan dan Sibu. Contohnya:

Jadual 3

Kesepadanan bunyi /r/dalam variasi Iban di Sarawak

\begin{tabular}{|c|c|c|c|}
\hline Maksud & Saribas & Samarahan & Sibu \\
\hline Rumah & rumeah & humeah & humeah \\
\hline Orang & urean & uhean & uhean \\
\hline Darah & dareah & daheah & daheah \\
\hline Kerak & kəreak & kəheak & kəheak \\
\hline
\end{tabular}

\section{konsonan $/-s /$.}

Konsonan /-s/ pada posisi akhir kata yang sepadan dengan bahasa Melayu baku turut menarik dibahaskan. Dalam variasi Ibanik seperti Demam, Sebaru', Bugau, Mualang, Seberuang, Banjur, dan Iban (Saribas dan Ulu Kapuas), kesepadanan untuk bunyi ini adalah: [-h] atau [-ç], lihat contoh berikut. 
Jadual 4

/-s/ dalam variasi-variasi Ibanik Sungai Ketungau

\begin{tabular}{|c|c|c|c|c|c|}
\hline Maksud & Demam & Sebaru' & Kumpang & Bugau & Banjur \\
\hline Putus & putuyç & putuyç & putuç & -- & putuç \\
\hline Tikus & -- & tikuyç & -- & -- & -- \\
\hline Lurus & -- & -- & -- & luвеh & -- \\
\hline Nipis & nipieyç & -- & $\operatorname{lipi}^{e^{e}} \zeta$ & nipeh & -- \\
\hline Manis & manieç & maniyç & manieç $^{\circ}$ & maneh & $\operatorname{mani}^{\mathrm{e}} \mathrm{c}$ \\
\hline Malas & -- & -- & lantu $^{e} c ̧$ & -- & -- \\
\hline Panas & panayç & -- & -- & paneah & -- \\
\hline
\end{tabular}

Jadual 5

/-s/ dalam variasi Ibanik Mualang

\begin{tabular}{cc}
\hline Maksud & Mualang (Chong, 2006) \\
\hline Putus & putuyh \\
Nipis & nipieyh \\
Manis & manieh \\
Panas & panayh \\
\hline
\end{tabular}

Jadual 6

/-s/ dalam variasi Iban Saribas dan Kapuas Hulu

\begin{tabular}{ccc}
\hline Maksud & $\begin{array}{c}\text { Iban Saribas } \\
\text { (Dedy, 2004) }\end{array}$ & $\begin{array}{c}\text { Iban Kapuas Hulu } \\
\text { (Penyusun, 2006) }\end{array}$ \\
\hline Putus & putuyh & putuyh \\
Tikus & -- & tikuyh \\
Lurus & -- & -- \\
Nipis & nipiey $^{\text {manh }}$ & -- \\
Manis & manie & maniyh \\
Malas & -- & -- \\
Panas & panayh & -- \\
\hline
\end{tabular}

Daripada perbincangan, dapat dirumuskan bahawa konsonan /s/ dan kesepadanan-kesepadanannya (dalam variasi-varasi Ibanik di Kalimantan Barat ataupun di Sarawak) merupakan alofon untuk/s/ pada posisi akhir kata. Pada posisi lain, /s/ tetap tampil sebagai [s]. Dalam kata lain, pada posisi akhir kata, /-s/ menunjukkan keberagaman variasi dalam bahasa Ibanik secara kumulatifnya. Berikut merupakan buktinya:

Jadual 7

Contoh /-s/sebagai alofon dalam variasi-variasi Ibanik di Sungai Ketungau

\begin{tabular}{cccccc}
\hline Maksud & Demam & Sebaru' & Bugau & Banjur & Kumpang \\
\hline Kuku & siluw? & siluw? & siluw? & silu? & siluw? \\
Besar & bəsaey & bəsay & bəsaey & bəsay & bəsay \\
Manis & manieç & maniyç & maneh & manieç & manie ${ }^{e}$ \\
\hline
\end{tabular}


Jadual 7 merupakan data Ibanik yang kesemuanya dituturkan di satu sistem sungai yang sama, iaitu Sungai Ketungau. Kalau diteliti, didapati alofon untuk /-s/ dalam variasi Demam, Sebaru' Banjur dan Kumpang adalah [ç]. Variasi Bugau kelihatan memaparkan kelainan, iaitu sebagai [h]; lihat juga Jadual 4. Faktor wujud perbezaan sedemikian sedangkan variasi ini turut tersebar di Sungai Ketungau? Hal ini dapat diterangkan dengan mengatakan bahawa variasi Bugau merupakan variasi tersendiri, yang secara fonologi berbeza dengan variasi Ibanik lain, seperti Demam, Sebaru', Banjur dan Kumpang. Dalam Jadual 8 berikut, deretan vokal yang mengalami geluncuran, iaitu [-auo-] atau [-auə-] pada variasi Demam, Sebaru', Banjur dan Kumpang didapati mengalami asimilasi dan wujud sebagai vokal belakang separa bundar panjang [ว:] pada variasi Bugau.

Jadual 8

Kelainan fonologi dalam variasi Bugau

\begin{tabular}{|c|c|c|c|c|c|}
\hline Maksud & Demam & Sebaru' & Banjur & Kumpang & Bugau \\
\hline Tahun & $\operatorname{tau}^{\curvearrowright} n$ & $\operatorname{tau}^{\curvearrowright} n$ & $\operatorname{tau}^{\curvearrowright} \mathrm{n}$ & $\operatorname{tau}{ }^{\curvearrowright} n$ & to:n \\
\hline Jauh & jauoh & jauoh & jauoh & jauoh & jد:h \\
\hline Daun & $\mathrm{dau}^{\ni} \mathrm{n}$ & $\mathrm{dau}^{\ni} \mathrm{n}$ & daun & daun & do:n \\
\hline
\end{tabular}

\section{Kesimpulan}

Kajian perbandingan terhadap ciri linguistik salah satu variasi Ibanik di Sungai Ketungau, iaitu variasi Kumpang telah menghasilkan beberapa penemuan dan mampu memperhalusi kajian terhadap bahasa Ibanik sebelum ini, misalnya yang telah dilakukan oleh Collins (2004) dan Chong (2006). Pertama, dari segi sistem vokal, variasi Kumpang hanya mengandungi empat vokal sahala, iaitu: /i/, /u/, /a/ dan /ə/. Jumlah vokal ini jauh kurang daripada variasi Ibanik lain, misalnya Iban di Saribas (Sarawak) dan Kantuk. Vokal /i/, /u/, /a/ berdistribusi pada semua posisi dalam kata, manakala /ə/ hanya tersebar pada posisi suku praakhir pada kata dwisilabik dan suku kedua, ketiga dari akhir pada kata trisilabik. Walaupun terdapat beberapa kata yang tampil dengan fonem [o], namun seperti isu /i/ dan /e/ dalam bahasa Melayu baku (misalnya [ade?] ditulis sebagai "adik"), [o] ditafsirkan sebagai alofon kepada [u]. Kedua, variasi Kumpang dikenal pasti mempunyai 19 konsonan dan 3 diftong. Dengan membandingkan konsonan-konsonan seperti geseran velar bersuara $/ \mathrm{\gamma} / \mathrm{dan}$ geseran alveolar tak bersuara /-s/ dengan variasi-variasi Ibanik lain, didapati variasivariasi Ibanik di Kalimantan Barat cukup diversiti dan kompleks dari segi fonologi. Buktinya ialah di Sungai Ketungau sahaja, terkandung variasi Ibanik yang tersendiri (iaitu variasi Bugau) dan variasi yang berbeza dialektal. 


\section{Rujukan}

Adelaar, K. A. (1987). Proto-Malayic: The reconstruction of its phonology and parts of its lexicon and morphology. Unpublished Ph.D dissertation, University of Leiden.

Chaer, A. (2003). Linguistik Umum. Jakarta: Rineka Cipta.

Chong, S. (2003, Mac). Research in Saribas Valley: An interim report. Kertas kerja yang dibentangkan di Workshop on Ethnic Minorities in Southeast Asia, Selangor, Malaysia.

Chong, S. (2006). Menilai distribusi dan ciri linguistik varian Ibanik. Dalam S. Chong, K. Harun, \& Y. Alas (Eds.), Reflections in Borneo Rivers: Essays in Honors of Professor James T. Collins, Book I (pp. 97-109). Pontianak: STAIN Pontianak Press.

Collins, J. T. (1987). Dialek Melayu Sarawak. Kuala Lumpur: Dewan Bahasa dan Pustaka.

Collins, J. T. (2004). Ibanic language in Kalimantan Barat, Indonesia: Exploring nomenclature, distribution and characteristic. Borneo Research Bulletin, 35, 17-47.

Dedy, A. A. (2004). Sastera lisan Sungai Saribas, Sarawak: Perspektif etnopuitika. (Tesis ijazah sarjana yang tidak diterbitkan). Universiti Kebangsaan Malaysia, Bangi, Malaysia.

Hudson, A. B. (1970). A note on Selako: Malayic Dayak and Land Dayak language in Western Borneo. Sarawak Museum Journal, 18(36-37), 301-318.

Lam, C. K. (2006). The Iban population of Sarawak: 1947-2000. Working Paper Series no. 13. Samarahan, Malaysia: Institute of East Asian Studies.

Penyusun, T. (2006). Kamus bahasa Iban. Pontianak: STAIN Pontianak Press.

Rahim, A. (2005). Perbandingan fonologi dan morfologi bahasa Iban, Kantuk dan Mualang. Kuala Lumpur: Dewan Bahasa dan Pustaka.

Remmy, G. (2009). Kepelbagai variasi Iban dan pemilihannya dalam berinteraksi. (Tesis ijazah sarjana yang tidak diterbitkan). Universiti Kebangsaan Malaysia, Bangi, Malaysia.

Sandin, B. (1968). Rajah Simpulang Gana. Kuching, Malaysia: Borneo Literature Bureau. 
Lampiran A: Lokasi Persebaran Variasi Ketungau dan Ketungau Sesat di Kalimantan Barat, Indonesia, didapati melalui http://www.google.com.

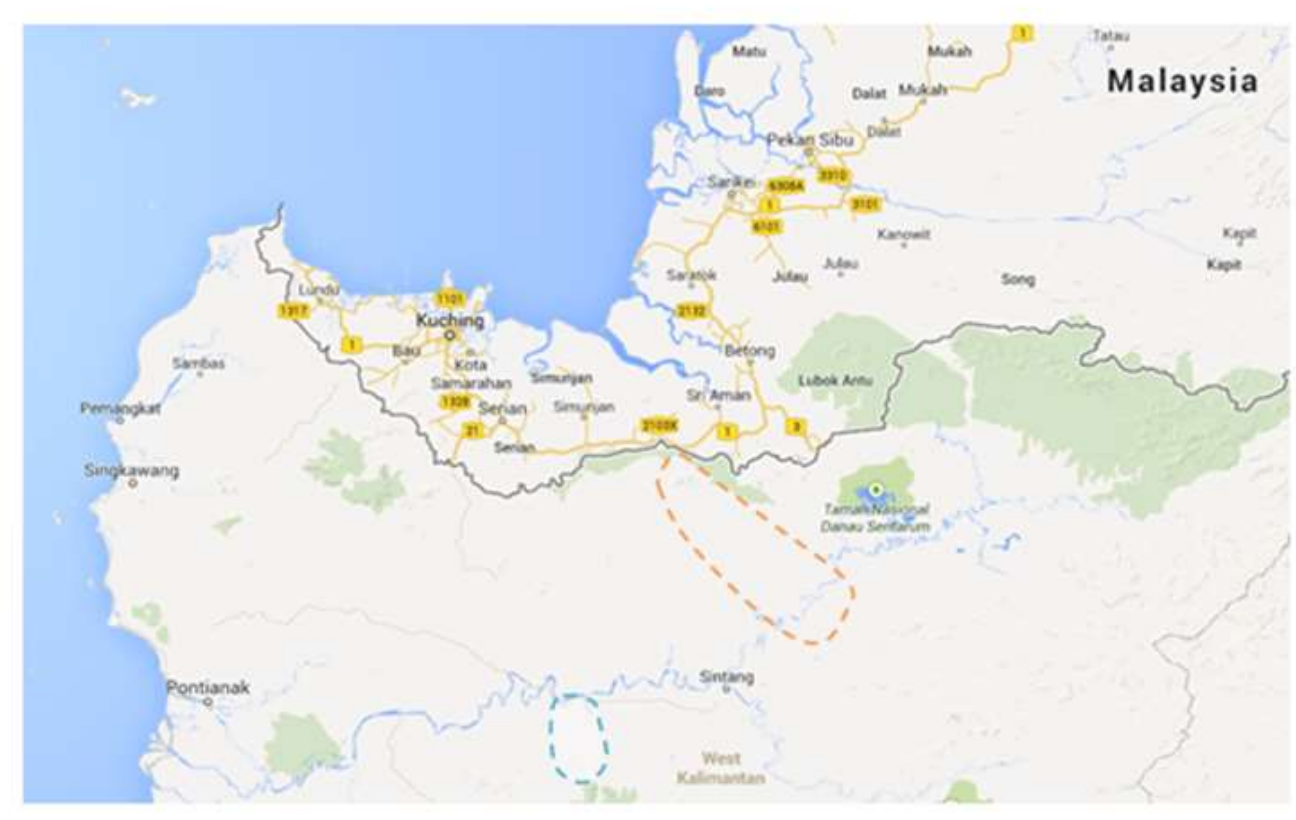

Kawasan persebaran variasi Ketungau

Kawasan persebaran variasi Ketungau Sesat 